\title{
Absolute price as a determinant of perceived service quality in hotels: a qualitative analysis of online customer reviews
}

\author{
Michail N. Giannakos* \\ Department of Computer and Information Science, \\ Norwegian University of Science and Technology (NTNU), \\ Sem Saelands vei 7-9, 7491 Trondheim, Norway \\ E-mail: michail.giannakos@idi.ntnu.no \\ *Corresponding author
}

\author{
Department of Informatics, \\ Ionian University, \\ Plateia Tsirigoti 7, 49100 Corfu, Greece \\ E-mail: ilpappas@ionio.gr \\ E-mail:mikalef@ionio.gr
}

Ilias O. Pappas and Patrick Mikalef

\begin{abstract}
User generated content and especially customer-generated reviews are becoming a prominent information source for travellers making hotel booking decisions. Building upon the dimensions of the SERVQUAL model, the aim of this study is to identify why hotel customers have disparate opinions regarding perceived service quality during their stays. In order to do so, we distinguish between high and low absolute priced hotels. We adopt this categorisation based on prior studies, which identify price as a strong determinant of hotel customers' perceptions and decisions. By applying qualitative data analysis methods on customer reviews from one of the world's leading online hotel reservation agencies (Booking.com), we show that absolute price has an impact on how customers perceive various dimensions of service quality. In particular, the number of positive reviews is significantly different for low and high priced hotels when examining the dimensions of tangibility and empathy. Additionally, our research reveals that the number of negative reviews also differentiates significantly for low and high priced hotels, not only for the dimensions of tangibility and empathy but also with regard to responsiveness and reliability. Based on these findings we highlight implications for researchers and practitioners and suggest future directions for research.
\end{abstract}

Keywords: user generated content; online hotel booking; price; SERVQUAL; convenience; perceived service quality.

Reference to this paper should be made as follows: Giannakos, M.N., Pappas, I.O. and Mikalef, P. (2014) 'Absolute price as a determinant of perceived service quality in hotels: a qualitative analysis of online customer reviews', Int. J. Hospitality and Event Management, Vol. 1, No. 1, pp.62-80. 


\begin{abstract}
Biographical notes: Michail N. Giannakos an is a ERCIM/Marie Curie Fellow in the Department of Computer and Information Science at the Norwegian University of Science and Technology (NTNU) and a Visiting Researcher in the Center for Real-time Computing, Virginia, USA. He holds a $\mathrm{PhD}$ in Educational Technology and Interaction Design; he has developed and experimented with learning environments since 2008, and since that time has single- or co-authored more than 50 manuscripts published in peer-reviewed journals and conferences. He is also a program committee member on several international conferences and a Guest Editor of the ACM Transactions on Computing Education and the International Journal of Emerging Technologies in Learning. He has worked at several research projects funded by diverse sources like EC, NSF, Microsoft Research and Cheng Endowment.
\end{abstract}

Ilias O. Pappas received his BSc in Informatics (specialisation in Humanities Informatics) from the Ionian University, Corfu, Greece and an MSc degree in Informatics (specialisation in Information Systems) from the same university. $\mathrm{He}$ is currently working on a $\mathrm{PhD}$ degree at the Ionian University. His current research interests are in the areas of electronic commerce, mobile commerce, information technology adoption, customer behaviour in online environments, personalisation and recommendation agents, and customer emotions in internet marketing.

Patrick Mikalef is currently a $\mathrm{PhD}$ candidate in the Department of Informatics at the Ionian University, Corfu, Greece. He holds a BSc in Informatics, with a specialisation on Information Systems from the Ionian University, and an MSc in Business Informatics in the Department of Information and Computing Sciences at the Utrecht University, Utrecht, The Netherlands. His research interests include information systems management, service-oriented architectures, digital business strategies, dynamic capabilities, and social media for business.

This paper is a revised and expanded version of a paper entitled 'Investigation of the hotel customers perceptions: a study based on user-generated content of online booking platforms' presented at the 2nd Advances in Hospitality and Tourism Marketing \& Management Conference, Corfu, Greece, 31 May to 3 June 2012.

\title{
1 Introduction
}

Consumers use a variety of information sources to infer the quality of goods and services. To this extent the internet has revolutionised the way hotel customers search information and compare facilities and accommodation before booking a hotel. However, identifying hotels that meet customer requirements has become a burden, primarily due to information overload on the web and because of distrust towards travel agent websites, which are often misleading. Due to these shortcomings consumers have turned to a more reliable source of information about hotel service quality, which is based on reviews by past visitors, provided through online booking systems (Bajari and Hortacsu, 2004; Ye et al., 2009). Information of this nature is termed user-generated content (UGC) and is growing at an increasing rate in both quantity and importance for the online hotel market (Ye et al., 2011). This phenomenon can be largely attributed to the rapid growth of Web 2.0 applications that facilitate UGC (Sigala, 2009).

Previous research has argued that absolute price has an impact on the way customers will express their satisfaction (Carvell and Quan, 2008; Yacouel and Fleischer, 2012). 
However, the impact of price as a determinant of expected service (ES) quality still remains unclear. To date the majority of studies have examined how reference price, as an aspect of a product or a service purchased, has an influence on the perceived value realised (Dodds et al., 1991). The rationale of these studies is based on the logic that a customer will relate the value of a product/service to its price. This association is also acknowledged as value-for-money (Sweeney and Soutar, 2001) and examines perceptions of quality under the prism of relative price paid. Therefore, the satisfaction that customers will express is dependent upon the relative price that they have paid (Bojanic, 1996). Although these studies may provide meaningful information regarding pricing schemes for products/services, they do not assess how customer expectations may vary based on an absolute price, and how these expectations impact their overall satisfaction. This is mainly because they do not examine the relationship between expectations and confirmation, and factors that shape these expectations. The expected value of a product or service is noted to be very different from the realised satisfaction (Sweeney and Soutar, 2001). This study aims to fill this gap by examining if the absolute price listing for a hotel has an impact on their expectations about service quality and in sequence their satisfaction, measured through positive of negative word-of-mouth. Our theoretical reasoning is grounded on the idea proposed in expectation-confirmation theory, which posits that consumers develop expectations; if these expectations are confirmed this will lead to satisfaction (Oliver, 1980). We suggest a variation of this argumentation, and postulate that expectations are influenced by absolute price, therefore satisfaction (expressed as positive or negative reviews) will be dependent upon the discrepancy between expected and realised service quality attributes. Consequently, we infer that satisfaction is indirectly influenced by the absolute price of a hotel.

In order to operationalise our research, an empirical study was conducted using data extracted from one of the world's leading online hotel reservation agencies. The dataset collected was comprised of customer-generated reviews retrieved from the online travel agency Booking.com (Priceline, NASDAQ: PCLN). Satisfaction was operationalised through the SERVQUAL (Parasuraman et al., 1985) framework as perceived service (PS) quality with the addition of convenience (Akbaba, 2006). Findings are expected to shed light on how to increase effectiveness of marketing strategies when promoting expensive and inexpensive hotels respectively.

To this end, the present study aims to identify those service quality dimensions that are of greatest importance for customers. Additionally, we examine how service quality perceptions differ for customers that select low and high absolute priced hotels. Therefore, the specific objectives of the study are as follows:

1 to identify which dimensions of service quality are more important (more frequently reported) from a customers' perspective in the hotel industry

2 to examine potential differences in each service quality dimension among customers that pay for expensive and inexpensive hotels.

The paper is structured as follows. In the next section, the theories underlying the key variables studied in the paper are discussed and our research hypotheses are presented. Section 3 presents the methodology as well as the procedures adopted for gathering and coding data from customer reviews. Section 4 presents empirical results, while the last section of the paper raises the key theoretical and practical implications of this research and discusses several ideas on further research in the area. 


\section{Theoretical background and research hypotheses}

\subsection{Service quality and online travel reviews}

Service quality refers to the ability to fulfil customers' requirements; both stated and implied (Lin and Su, 2003). Regarding the hotel industry, PS quality refers to how well customer expectations are met by the hotelier. The degree to which service quality criteria are met is considered as an important determinant of hotel customers' satisfaction and acceptance (Christou, 2006). Hence, service quality is regarded as a highly important aspect and has been identified as an enabler of a competitive advantage in the hotel industry (Yang and Yang, 2011).

However, measuring the quality of a service is a complex task as opposed to when measuring the quality of goods. This is primarily due to the multi-dimensional and subjective nature of services. Despite this fact, a number of proposed frameworks have been put forth, with one of the most popular and successful assessment tools of service quality being SERVQUAL, originally proposed by Parasuraman et al. (1985). While the SERVQUAL framework was originally measured by employing ten dimensions of service quality, a later version by Parasuraman et al. (1988) merged them into five. The five dimensions of the later framework include Tangibility (TANG), Reliability (REL), Responsiveness (RES), Assurance (ASS), and Empathy (EMP). The definitions for each of the dimensions are listed below (Parasuraman et al., 1988):

1 Tangibility includes the physical evidence of services, such as physical facilities, tools or equipment, appearance of employees, and other customers.

2 Reliability involves the consistency of performance and dependability. It means that the firm performs the service correctly for the first time and honours its promise.

3 Responsiveness concerns the willingness or readiness of employees to provide service. It involves timeliness of services (e.g., setting up an appointment quickly).

4 Assurance refers to the knowledge, courtesy of employers and their ability to convey trust and confidence.

5 Empathy means providing attention to every individual customers demands by the staff.

Based on suggestions from literature we incorporate the dimension of Convenience as an additional aspect of service quality (Kumar et al., 2010). Convenience has been noted as being of paramount importance for hotel customers, to such an extent that it could possibly affect their overall evaluation of service quality (Akbaba, 2006; Berry et al., 2006). This dimension of service quality emphasises on hotel location, and the ease and adequacy of offered services, an aspect especially important to customers with a busy agenda.

6 Convenience means accessibility and ease for the customers.

Therefore, this study is grounded on the extended SERVQUAL framework, which is comprised of the six aforementioned dimensions.

Service quality is often conceptualised as the comparison of service expectations with actual service perceptions (Pizam and Ellis, 1999). According to a study by Pizam and Ellis (1999), service quality leads to the attraction of new customers and leads to an 
overall increase of business performance. Consequently, the reliability of information provided to consumers is critical, since it has a direct impact on the expected level of service quality and their reaction to the actual service provided.

Information gathering by consumers is performed both online and offline, however, online transactions are rapidly gaining momentum and replacing traditional methods (Buhalis and Licata, 2002). The information gathering procedure has been greatly improved by the appearance of online travel agencies, which provide consumers with an effective way of gathering information regarding hotels and their facilities. Through such online travel agencies (e.g., Booking.com, Expedia.com) consumers can browse through a list of hotels at a specific destination, find and compare hotel information (e.g., prices, star rating, location, facilities) and book the one of their preference. In the evaluation and selection of the hotel to be booked, consumers rely at a growing rate on comments made by past customers. Such online travel reviews are defined as user generated content that is usually posted on hotel, company or travel agent websites (Ye et al., 2009). The reviews posted are in most cases rich in information about service quality aspects, post experience evaluation as well as overall evaluation. Gretzel and Yoo (2008) found that almost all potential travellers find reviews to be helpful when making a decision, by increasing the likelihood of congruency between expectations and actual purchases. Also, based on reviews customers may be able to get new ideas or find alternative ones. Online travel reviews are advantageous in examining customers' perceptions, and compared to other methods such as questionnaires or interviews, they are considered as a compelling and more reliable method to investigate those perceptions (Ye et al., 2012).

The SERVQUAL framework has been employed as the theoretical basis in many empirical studies for measuring customers' PS quality (Devaraj et al., 2002). The principal advantage of SERVQUAL is that it has been proven to be applicable across a large range of service contexts. Parasuraman et al. (1991) indicate that SERVQUAL could undergo minor modifications in order to be valid in almost any context. To date, SERVQUAL has been applied in various settings of the hotel industry; including consumer opinions, IT services, and healthcare areas (Albacete-Sáez et al., 2007). The methodology by which the SERVQUAL instrument has been operationalised is primarily through surveys. In the present study, the dimensions that comprise the SERVQUAL frameworks are extracted by using novel approaches on customer electronic reviews. These reviews were obtained from one of the leading travel agency websites on which content analysis techniques were applied in order to classify the content into one or more dimensions of the modified SERVQUAL instrument. The prime differentiator with past studies is that the approach followed in this study centres on those dimensions of service quality which consumers regard as most important, i.e., those that are mentioned in their reviews.

\subsection{Pricing in hospitality industry and research hypotheses}

In their attempt to deal with The Lemon Problem (Akerlof, 1970) within the hotel industry, professional certifiers were developed in order to rate hotel facilities (five-star rating systems). The main idea of these certifiers is to provide potential customers with a quantified measure of the service and facilities to be expected by a hotel. However, these rating systems mainly reflect physical attributes and not customers' attitudes, they are not always reliable, and each country may base their scaling on different standards (Yacouel 
and Fleischer, 2012). Before the emergence of the internet, travel agents and tour operators served as intermediaries between hoteliers and prospective guests, helping with the search and selection process, thus mitigating the information asymmetry problem. Clerides et al. (2008) examined the role of travel agencies as reliable quality assessors in the hotel market as they directly connected with the market and found that the travel agencies' rating of hotels was better matched with prices than with the national five-star system. Although pricing methods refer to the specific formulas used in order to set a price and include several aspects (e.g., discounts, coupons), pricing policies are associated with the actual prices (Lowengart and Mizrahi, 2000). The main underlying goal of the above studies is to develop a better fit between quality criteria and pricing, thus mitigating the problem of information asymmetry. The main premise of these investigations is that price should be appropriated in such a way in order to provide hotel customers of an indication of the quality attributes that should be expected. Since relative price is a measure that rates price towards service quality perceived, and requires that consumers have utilised the product service, it a measure that we deem as unfit to impact on consumers' expectations regarding service quality. Hence, we employ the measure of absolute price to determine how it may impact consumers' expectations. Since the discrepancy between expectations and actual service will determine the PS quality we advocate that absolute price is an important determinant of overall consumer satisfaction.

Cunningham et al. (2002) reported significant differences in service quality perceptions among customers with different characteristics. Differentiated pricing involves offering different prices to customers on the basis of numerous criteria. In general, customers tend to form higher quality perceptions and give higher rating to hotels, when the price they paid for a room seems to be cheaper than it should be (Oh, 2003). This idea is grounded on the price measure as a relative price, since what is considered as cheap and expensive is subjective. In this research we investigate how PS quality differentiates on the basis of actual and not perceived price. Our prime target is to identify if expensive and inexpensive hotels impact consumers perceptions about the quality of service offered to them. Ye et al. (2012) found that when customers evaluate a hotel, the actual price paid positively affects their PS quality. This implies that the service quality expectations increase in accordance with the paid price. This association is more significant when examining expensive hotels, with the negative association between inexpensive hotels and PS quality being dampened.

In their study, Parasuraman et al. (1985) advocate that realised service quality depends on the discrepancy between ES and PS. Ladhari (2009) define behavioural intentions as a factor influenced by willingness to pay more money and mention that favourable behavioural intentions include paying a premium price. They found that these intentions are positively affected by PS quality. Consequently, it is likely that a relation exists between the willingness to pay more and PS quality and its dimensions, although such relation is not examined on Ladhari (2009). This disparity is evident in the case of expensive hotels from which consumers expect a high level of service quality (Ye et al., 2012). This association of price being a determinant of service quality is also noted in literature (Bitner and Hubbert, 1994). Hence, the quality of service expected by customers relies on the price that they have paid (Briggs et al., 2007). Extending on this notion, it can be inferred that low absolute priced hotels are not expected to offer high quality services; therefore, customers will have lower expectations. This means that the effort required from hoteliers to cover these requirements is significantly less in 
comparison with expensive hotels, leading in sequence to higher levels of PS quality by customers.

Numerous studies have examined the idea of service quality at the level of the SERVQUAL dimensions, looking at them in isolation. One of these studies conducted by Hartman (1989) found that business travellers exhibit a willingness to pay for amenities such as room service, availability of parking, and guaranteed reservations in a luxury hotel, linking as such price with service quality. Monty and Skidmore (2003) extended findings in this matter and identified facilities such as a hot tub, a private bath and a larger room as having an impact on the price paid. Based on the above findings we can assume that hotel customers that pay a high absolute price will have high expectations regarding the tangibility dimension of service quality. Collins and Parsa (2006) identified many factors that influence pricing decisions, including location, size and amenities, which place emphasis on the importance of tangibility as well as that of convenience. A study by Briggs et al. (2007) found that the main reason for low PS quality was related to the absence of a personal touch and the way that which the hotel dealt with complaints, thus highlighting the importance of empathy and assurance. Zhang et al. (2011) found that the first requirement for expensive hotel customers is location, which is an element of convenience, while tangibility factors (e.g., room design, facilities) are the most important ones for customers of absolute low priced hotels. The aforementioned studies link hotel facilities and service quality with a price, thus showing that customers will pay more for additional services. Reversing this logic and supported on the findings on Webster (1991), which notes that customers are affected by past experiences, we postulate that customers who pay for expensive hotels have high expectations of service quality. Since positive feedback (an outcome of satisfaction) is a result of expectations being surmounted and desired service quality attributes being fulfilled, we advocate that in the case of expensive hotels the margin to do so is limited in comparison to inexpensive hotels (Zeithaml and Berry, 1993). Therefore, positive feedback regarding the PS quality dimensions for customers of expensive hotels will be significantly less than those of inexpensive hotels. Following the same train of thought, we postulate that expectations of customers of low absolute priced hotels can easily be met to the adequacy level. Hence, it is more likely that the number of negative comments by hotel customers of this category will be significantly less than those of high absolute priced hotels.

In our study, we measure PS quality using dimensions adopted from previous studies (Chang, 2009; Fernández and Bedia, 2005; Juwaheer, 2004; Voss, 2003). Based on the above argumentation we develop the following hypotheses:

H1a High paying hotel customers have significantly fewer positive reviews regarding empathy than low paying hotel customers.

H1b High paying hotel customers have significantly more negative reviews regarding empathy than low paying hotel customers.

H2a High paying hotel customers have significantly fewer positive reviews regarding convenience than low paying hotel customers.

$\mathrm{H} 2 \mathrm{~b}$ High paying hotel customers have significantly more negative reviews regarding convenience than low paying hotel customers.

H3a High paying hotel customers have significantly fewer positive reviews regarding reliability than low paying hotel customers. 
H3b High paying hotel customers have significantly more negative reviews regarding reliability than low paying hotel customers.

H4a High paying hotel customers have significantly fewer positive reviews regarding assurance than low paying hotel customers.

H4b High paying hotel customers have significantly more negative reviews regarding assurance than low paying hotel customers.

H5a High paying hotel customers have significantly fewer positive reviews regarding responsiveness than low paying hotel customers.

H5b High paying hotel customers have significantly more negative reviews regarding responsiveness than low paying hotel customers.

The only exception to this rationale is the service quality dimension of tangibility, because hotel customers exhibit high willingness to pay for such attributes (Hartman, 1989 ) and this dimension is much more objective than the previous five and the only one that is intangible. According to the study by Johnston (1995), tangible aspects of service quality are usually perceived as less important and it is therefore less likely that customers will make negative reviews. This applies especially for expensive hotels, in which hoteliers place much effort (interior design, furniture, etc.). However, in inexpensive hotels, which usually manage to offer low prices due to the absence of tangible artefacts, we assume that customers will not focus on posting positive comments. As such, we propose that there is a significant positive difference on the disparity between ES and PS, among the high and low paying hotel customers; hence the following hypotheses are formulated:

H6a High paying hotel customers have significantly more positive reviews regarding tangibility than low paying hotel customers.

H6b High paying hotel customers have significantly fewer negative reviews regarding tangibility than low paying hotel customers.

\section{Research methodology}

\subsection{Data collection}

The data used in this study were retrieved from Booking.com (Priceline, NASDAQ: PCLN), one of the world's leading online hotel reservations agencies. Booking.com allows past hotel guests who have booked a hotel room through their website to write reviews. Consequently, there are no unreliable posts by users that have not stayed at the hotel... In addition, Booking.com also monitors the hotel descriptions published on its website, ensuring that the hotels' actual informative data match those that are published.

For the data collection procedure (Figure 1), ten large cities and popular holiday destinations were randomly selected from the USNews ${ }^{1}$ and then ten customer reviews (including positive and negative as provided by Booking.com based on customers' categorisation) of ten hotels (five expensive and five inexpensive based on Booking.com price ranks) of each city were selected. 
Figure 1 Data collection procedures

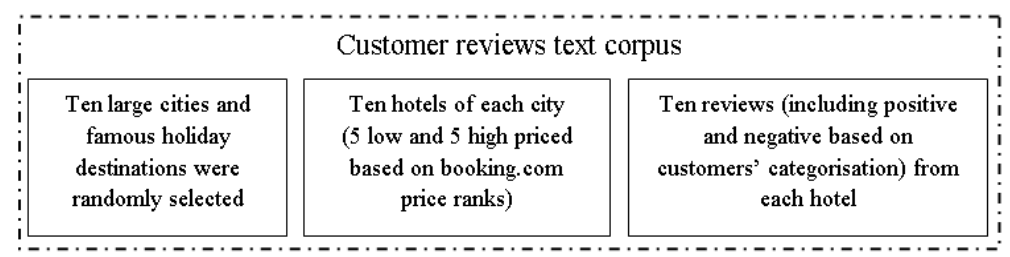

These reviews covered a text corpus of approximately 120 pages. Roughly half of the corpus represents expensive hotels and the rest concerns inexpensive ones. In addition, the corpus almost equally represents positive and negative comments. By following these data collection procedures (Figure 1), we achieved to have four equally representative categories. As such, from the total of 120 pages, four categories (positive-inexpensive, positive-expensive, negative-inexpensive and negative-expensive) with almost the same length (30 pages) were identified.

\subsection{Coding procedures and protocol}

After completing the customer reviews collection (text corpus), we proceeded in performing a qualitative text analysis of the case studies. The methodology of Mayring (2000) was selected, which combines several techniques for text analysis into a systematic process. According to Mayring (2000), the category system or coding categories might derive either from an existing theory (deductive category application), or develop during the analysis from the text corpus (inductive category development). In our case we used SERVQUAL as our theoretical basis and in conjunction with literature suggestions (Akbaba, 2006; Kumar et al., 2010) decided to include the dimension of convenience. For the coding procedure and for the evaluation of the coding results (Figure 2), we employed the software package MaxQDA (http://www.maxqda.com).

Figure 2 Coding procedure through MaxQDA, (a) the code categories 'system' (b) and the text corpus (see online version for colours)

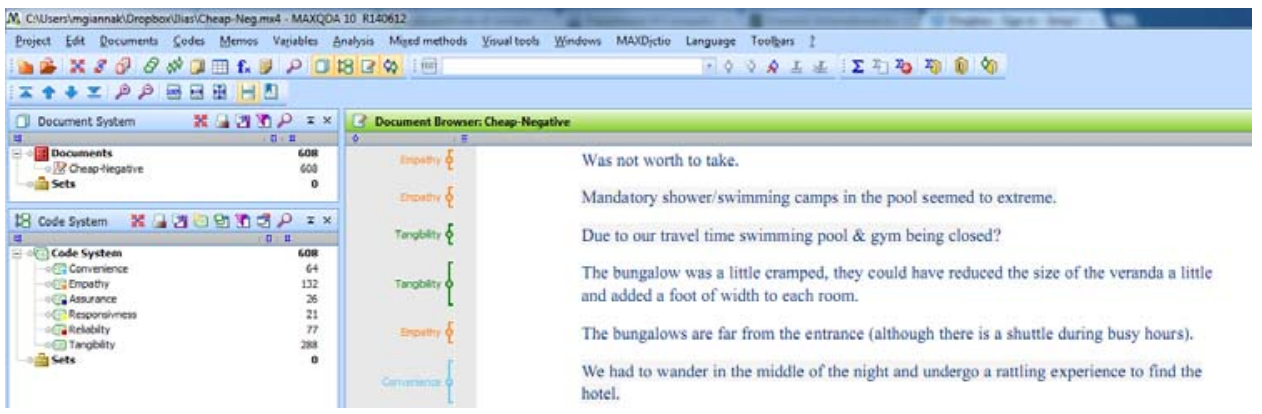

(a)

(b)

In particular for the coding, two researchers with experience on qualitative analysis and the SERVQUAL framework coded the text corpus (customer reviews) independently. In order to facilitate the work of the two researchers prior to the coding we developed and 
assisted them with the following coding protocol (Table 1), which contains the operational definitions of dimensions followed by an example for each dimension separately as identified in the literature.

Table 1 Coding protocol

\begin{tabular}{|c|c|c|}
\hline Dimensions & Definition & Example \\
\hline Empathy (EMP) & $\begin{array}{l}\text { The provision of caring, } \\
\text { individualised attention the firm } \\
\text { provides its customers. }\end{array}$ & $\begin{array}{l}\text { The staff acknowledges customers at } \\
\text { the reception with a verbal greeting. }\end{array}$ \\
\hline $\begin{array}{l}\text { Convenience } \\
\text { (CONV) }\end{array}$ & $\begin{array}{l}\text { Convenience involves comfort, } \\
\text { accessibility and easiness to the } \\
\text { customers. }\end{array}$ & $\begin{array}{c}\text { Hotel locates in the great area } \\
\text { (near centre, train station, bus station, } \\
\text { airport, etc.). }\end{array}$ \\
\hline $\begin{array}{l}\text { Reliability } \\
\text { (REL) }\end{array}$ & $\begin{array}{l}\text { The ability to perform the } \\
\text { promised services dependably } \\
\text { and accurately. }\end{array}$ & $\begin{array}{l}\text { The staff performs tasks that have been } \\
\text { promised to guests and resolves any } \\
\text { problem encountered. }\end{array}$ \\
\hline Assurance (ASS) & $\begin{array}{l}\text { The knowledge and courtesy of } \\
\text { employees and their ability to } \\
\text { convey trust and confidence. }\end{array}$ & $\begin{array}{c}\text { The staff can handle effectively } \\
\text { complaints and problems from the } \\
\text { guests. }\end{array}$ \\
\hline $\begin{array}{l}\text { Responsiveness } \\
\text { (RES) }\end{array}$ & $\begin{array}{l}\text { The willingness to help } \\
\text { customers and provide prompt } \\
\text { service. }\end{array}$ & $\begin{array}{l}\text { The customers are offered alternative } \\
\text { accommodation at a nearby hotel. } \\
\text { Reservation cards are ready to sign } \\
\text { upon arrival. }\end{array}$ \\
\hline $\begin{array}{l}\text { Tangibility } \\
\text { (TANG) }\end{array}$ & $\begin{array}{l}\text { The appearance of physical } \\
\text { facilities, equipment, personnel } \\
\text { and communication materials. }\end{array}$ & The front office staff is well dressed. \\
\hline
\end{tabular}

\section{Research findings}

After the coding procedures, 3,693 codes were identified. A Cohen kappa test was conducted to examine the inter-reliability of the coding. The number of codes and the index of reliability at each category are presented in Table 2.

Table 2 Index reliability

\begin{tabular}{lccc}
\hline Review category & Hotel category & Codes & Cohen kappa \\
\hline Positive & Inexpensive & 1,083 & 0.82 \\
Positive & Expensive & 1,028 & 0.78 \\
Negative & Inexpensive & 723 & 0.70 \\
Negative & Expensive & 859 & 0.74 \\
\hline
\end{tabular}

Every category surpassed the recommended threshold (Cohen kappa $=0.70)$ (Lombard et al., 2010), indicating high inter-coder reliability. Table 3 exhibits the exact results of the coding procedure. 
Table 3 Coding results

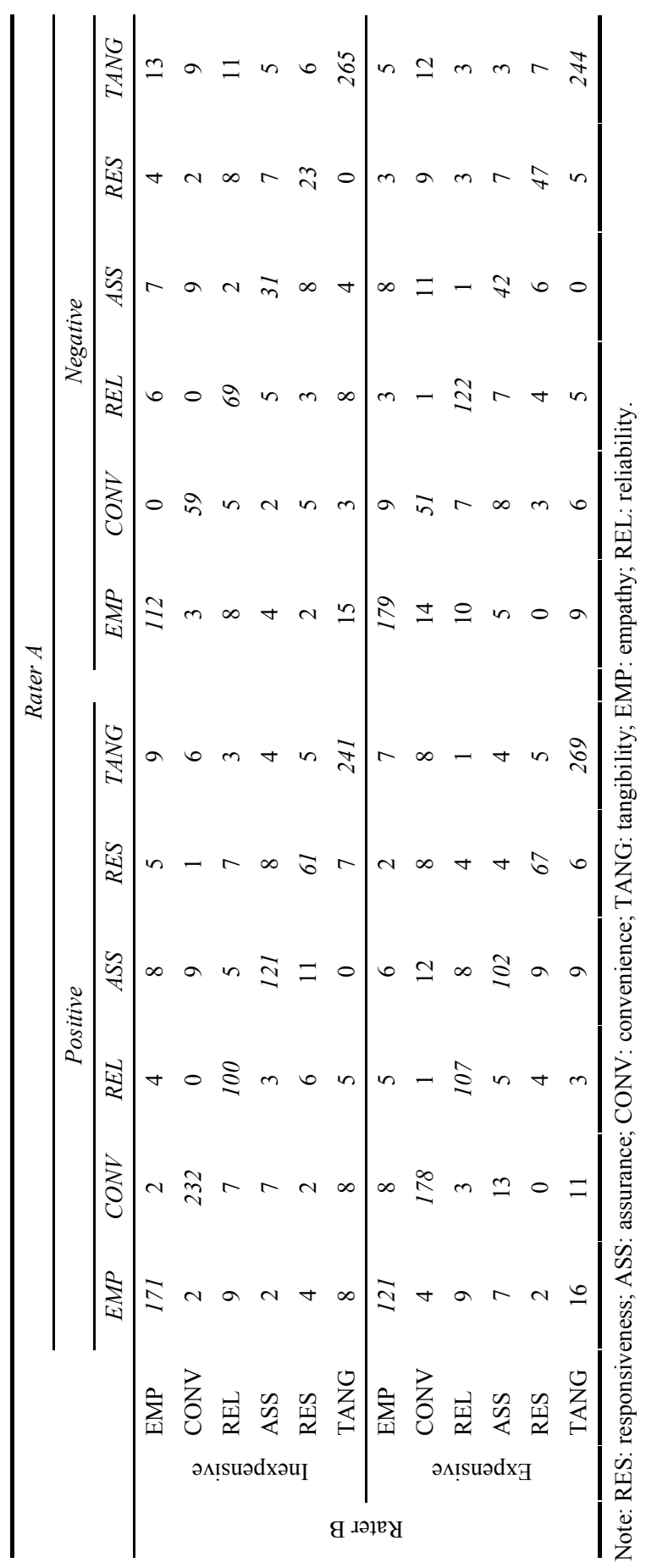


From the total of 3,693 codes we have an agreement on 3,014 codes. Based on the agreement codes, we identify the following service dimensions, which are presented in descending order (Table 4).

Table 4 Frequency appearance priority of service dimensions based on the number of customer reviews

\begin{tabular}{lc}
\hline Dimensions prioritised by the frequency they reported & No. of codes (\%) \\
\hline Tangibility (TANG) & $1,019(33.81 \%)$ \\
Empathy (EMP) & $583(19.34 \%)$ \\
Convenience (CONV) & $520(17.25 \%)$ \\
Reliability (REL) & $398(13.21 \%)$ \\
Assurance (ASS) & $296(9.82 \%)$ \\
Responsiveness (RES) & $198(6.57 \%)$ \\
\hline
\end{tabular}

From the total agreement codes, $1,770(58.73 \%)$ are positive and $1,244(41.27 \%)$ are negative, 1,485 (49.27\%) are generated for inexpensive and 1,529 (50.73\%) for expensive hotels. In particular, $926(30.72 \%)$ of the codes are positive and generated from customers of low absolute priced hotels, $844(28.00 \%)$ of the codes are positive and generated from customers of high absolute priced hotels, $559(18.55 \%)$ of the codes are negative and generated from customers of low absolute priced hotels and $685(22.73 \%)$ of the codes are negative and generated from customers of high absolute priced hotels. The descriptive statistics in Table 4 present the coding frequency of each dimension. To examine the differences on the number of reviews in each quality dimension amongst customers of high and low priced hotels, a Pearson's chi-square test was conducted. The results of chi-square test are summarised in the following table (Table 5).

Table 5 Descriptive statistics and Pearson's chi-square test results between customers of expensive and inexpensive hotels

\begin{tabular}{|c|c|c|c|c|c|c|c|c|c|c|c|}
\hline \multirow{3}{*}{ Factors } & \multicolumn{2}{|c|}{ Positive } & \multirow{3}{*}{ Sign. } & \multirow{3}{*}{$C h i$} & \multirow{3}{*}{$d f$} & \multirow{3}{*}{ Result } & \multicolumn{2}{|c|}{ Negative } & \multirow{3}{*}{ Sign. } & \multirow{3}{*}{ Chi } & \multirow{3}{*}{$d f$ Resul } \\
\hline & \multicolumn{2}{|c|}{ Codes (\%) } & & & & & Codes & $(\%)$ & & & \\
\hline & Inexpensive & Expensive & & & & & Inexpensive & Expensive & & & \\
\hline EMP & $\begin{array}{c}171 \\
(5.67 \%)\end{array}$ & $\begin{array}{c}121 \\
(4.01 \%)\end{array}$ & $0.048^{*}$ & 3.93 & 1 & $\begin{array}{l}\text { H1a } \\
\text { (A) }\end{array}$ & $\begin{array}{c}112 \\
(3.72 \%)\end{array}$ & $\begin{array}{c}179 \\
(5.94 \%)\end{array}$ & $0.046^{*}$ & 3.98 & $\begin{array}{cc}1 & \text { H1b } \\
& \text { (A) }\end{array}$ \\
\hline CONV & $\begin{array}{c}232 \\
(7.70 \%)\end{array}$ & $\begin{array}{c}178 \\
(5.91 \%)\end{array}$ & 0.119 & 2.44 & 1 & $\begin{array}{l}\mathrm{H} 2 \mathrm{a} \\
(\mathrm{R})\end{array}$ & $\begin{array}{c}59 \\
(1.96 \%)\end{array}$ & $\begin{array}{c}51 \\
(1.69 \%)\end{array}$ & 0.079 & 3.08 & $\begin{array}{cc}1 & \mathrm{H} 2 \mathrm{~b} \\
& (\mathrm{R})\end{array}$ \\
\hline REL & $\begin{array}{c}100 \\
(3.32 \%)\end{array}$ & $\begin{array}{c}107 \\
(3.55 \%)\end{array}$ & 0.275 & 1.19 & 1 & $\begin{array}{l}\mathrm{H} 3 \mathrm{a} \\
(\mathrm{R})\end{array}$ & $\begin{array}{c}69 \\
(2.29 \%)\end{array}$ & $\begin{array}{c}122 \\
(4.05 \%)\end{array}$ & $0.022^{*}$ & 5.22 & $\begin{array}{cc}1 & \text { H3b } \\
& \text { (A) }\end{array}$ \\
\hline ASS & $\begin{array}{c}121 \\
(4.01 \%)\end{array}$ & $\begin{array}{c}102 \\
(3.38 \%)\end{array}$ & 0.584 & 0.30 & 1 & $\begin{array}{l}\mathrm{H} 4 \mathrm{a} \\
(\mathrm{R})\end{array}$ & $\begin{array}{c}31 \\
(1.03 \%)\end{array}$ & $\begin{array}{c}42 \\
(1.39 \%)\end{array}$ & 0.68 & 0.17 & $\begin{array}{cc}1 & \mathrm{H} 4 \mathrm{~b} \\
& (\mathrm{R})\end{array}$ \\
\hline RES & $\begin{array}{c}61 \\
(2.02 \%)\end{array}$ & $\begin{array}{c}67 \\
(2.22 \%)\end{array}$ & 0.308 & 1.04 & 1 & $\begin{array}{l}\mathrm{H} 5 \mathrm{a} \\
\text { (R) }\end{array}$ & $\begin{array}{c}23 \\
(0.76 \%)\end{array}$ & $\begin{array}{c}47 \\
(1.56 \%)\end{array}$ & $0.048^{*}$ & 3.92 & $\begin{array}{cc}1 & \mathrm{H} 5 \mathrm{~b} \\
& \text { (A) }\end{array}$ \\
\hline TANG & $\begin{array}{c}241 \\
(8.00 \%)\end{array}$ & $\begin{array}{c}269 \\
(8.93 \%)\end{array}$ & $0.044^{*}$ & 4.06 & 1 & $\begin{array}{l}\text { H6a } \\
\text { (A) }\end{array}$ & $\begin{array}{c}265 \\
(8.79 \%)\end{array}$ & $\begin{array}{c}244 \\
(8.10 \%)\end{array}$ & $0.007 * *$ & 7.37 & $\begin{array}{cc}1 & \text { H6b } \\
& \text { (A) }\end{array}$ \\
\hline Total & $\begin{array}{c}926 \\
(30.72 \%)\end{array}$ & $\begin{array}{c}844 \\
(28.00 \%)\end{array}$ & & & & & $\begin{array}{c}559 \\
(18.55 \%)\end{array}$ & $\begin{array}{c}685 \\
(22.73 \%) \\
\end{array}$ & & $14(10$ & $00 \%)$ \\
\hline
\end{tabular}

Notes: Significance level, $* * p<.01 ; * p<.05$. EMP: empathy; CONV: convenience;

REL: reliability; ASS: assurance; RES: responsiveness; TANG: Tangibility;

(A): accepted; (R): rejected. 
As Table 5 shows, in the case of positive reviews, the price paid exhibits significant effect on the tangibility and empathy dimensions. Observing the number of codes, customers make significantly more positive comments regarding the tangibility dimension of expensive hotels. On the other hand, customers of high absolute priced hotels make significantly fewer positive comments regarding the empathy dimension. For the case of negative reviews, the price paid exhibits significant impact on the responsiveness, tangibility, empathy and reliability dimensions. Observing the number of codes, customers of high absolute priced hotels make significantly more negative comments regarding the responsiveness, empathy and reliability dimensions. On the other hand, customers of low absolute priced hotels make significantly more negative comments regarding the tangibility dimension.

\section{Discussion and conclusions}

We have examined how the absolute price of hotels impacts the perceived quality of services realised by customers. The attribute of quality is examined through a novel approach by using customer electronic reviews (word-of-mouth) posted on a travel agency website. We reverse the directionality of hypotheses of Zhang et al. (2011) who examine what hotel attributes lead customers an increased willingness to pay, and find that the price paid by hotel customers has a significant impact on how they perceive different elements of service. This is done by codifying online customer reviews according to the dimensions of SERVQUAL with the addition of convenience. Grounded on past studies regarding cost-quality associations, we develop a set of hypotheses (H1a-H6a and H1b-H6b) which are then analysed. Findings reveal that several dimensions of PS quality are significantly differentiated based on the absolute pricing of the hotel. In particular, the dimensions of responsiveness, tangibility, empathy and reliability exhibit such a differentiation.

As the majority of the reviews address it, tangibility is the most important dimension (more frequently reported) from the customers' perspective (Table 4). Through the analysis of this specific dimension, we find that customers of high absolute priced hotels make significantly more positive comments than those of inexpensive hotels (H6a accepted) and customers of low absolute priced hotels make significantly more negative reviews than those of high absolute priced hotels (H6b accepted). However, this may be based on the fact that expensive hotels have more facilities and as a result customers of expensive hotels make more positive and fewer negative comments. Ergo, it seems that the hotel price reduction does not affect customers' perceptions regarding the lack of some facilities.

For the dimensions of assurance and convenience there is no significant difference between the number of reviews (positive and negative) for customers of expensive and inexpensive hotels (H2a,b and H4a,b are rejected). In addition, observing Figure 3 we can infer that customers' perceived convenience and assurance are important supplementary services of a hotel (due to the many positive reviews) and not important requirements (due to the few negative reviews in Figure 4). On the one hand regarding assurance, our results are partially consistent with previous studies that found assurance factors (e.g., courteous staff) to be a desirable service but not a requirement for expensive hotels (Zhang et al., 2011). On the other hand with regard to convenience, our results partially 
contradict Zhang et al. (2011), who found it to be the most important requirement for high paying customers. For the case of empathy, there is a significant difference between the number of reviews (both positive and negative) customers of expensive and inexpensive hotels ( $\mathrm{H} 1 \mathrm{a}$ and $\mathrm{H} 1 \mathrm{~b}$ are accepted). These results verify that customers of expensive hotels have high expectations for the empathy dimension. The dimension of reliability has great similarity in the number of reviews in each category (Figures 1 and 2 ). Regarding the positive reviews, there is no significant difference between customers of low and high absolute priced hotels ( $\mathrm{H} 3 \mathrm{a}$ is rejected). For negative reviews however, there is a significant difference since customers of expensive hotels have made significantly more negative comments. Therefore, $\mathrm{H} 3 \mathrm{~b}$ is accepted and verifies the difference in perception of service quality for customers of expensive and inexpensive hotels.

Figure 3 Frequency of positive reviews from customers of low and high absolute priced hotels on every dimension (see online version for colours)

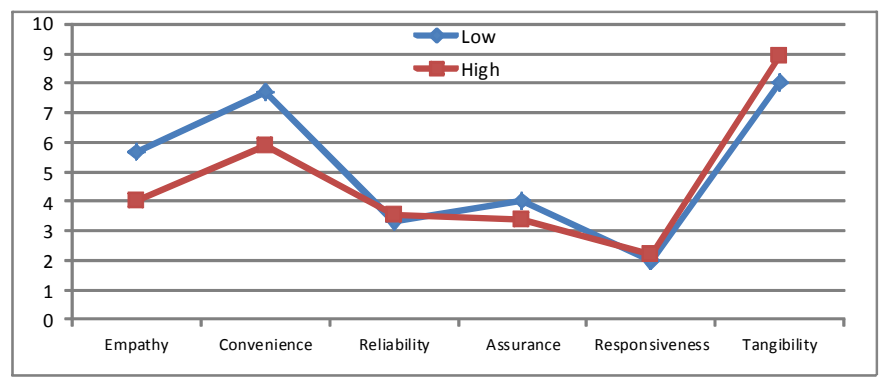

As for the assurance dimension, there is no significant difference between the number of positive and negative reviews ( $\mathrm{H} 4 \mathrm{a}$ and $\mathrm{H} 4 \mathrm{~b}$ are rejected). Responsiveness involves the prompt and proactive response towards customer needs. The results on this dimension indicate an insignificant difference on the number of positive reviews (H5a rejected) and a significant difference on the number of negative reviews (H5b accepted). Hence, customers of expensive hotels have made significantly more negative reviews with regard to this dimension. As a result responsiveness is not regarded as an optional service (due to $\mathrm{H} 5 \mathrm{a}$ rejection) but as prerequisite (due to $\mathrm{H} 4 \mathrm{~b}$ acceptance).

Figure 4 Frequency of negative reviews from customers of low and high absolute priced hotels on every dimension (see online version for colours)

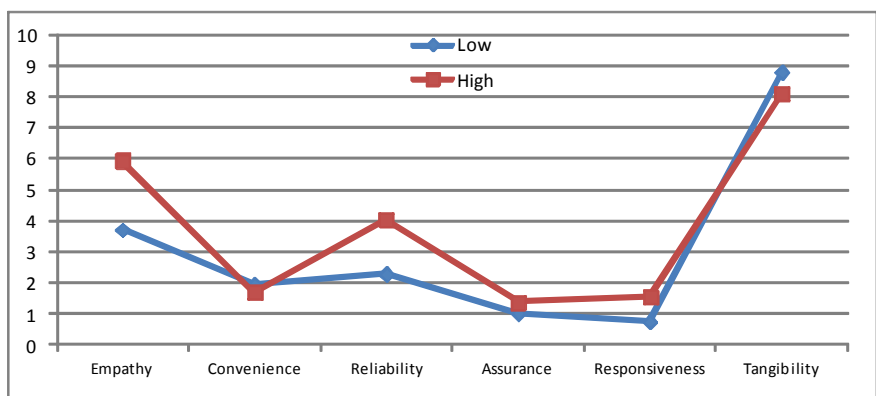




\subsection{Implications}

The main theoretical implication of this research relates to filling in the knowledge gap of the impact of absolute price paid on the prime determinants of visitors' PS quality based on online customer-generated reviews. This study measures the six key quality dimensions and provides meaningful results for each price and review category. In addition, the research findings reveal differences in many quality service dimensions between hotel customers of expensive and inexpensive hotels. Marketing strategies must be differentiated and focused on the appropriate quality attributes, as some dimensions appear to be more important for hotel customers. Thus, owners of inexpensive hotels should focus on increasing their empathy-related services, while owners of expensive hotels should focus their efforts in increasing responsiveness, tangibility and reliability of their services.

These results address a few shortcomings of previous studies on the area. Specifically, Stringam and Genders (2010) used customer online reviews to identify important commendations and concerns. Their study identified words and not dimensions; they found that cleanliness was the most important concern of the travellers, with location and comments about the staff following. Even though the identified words may be categorised to the specific dimensions of the SERVQUAL construct, not all dimensions can be included. Moreover, Stringam and Genders (2010) did not investigate the different effects of the price paid by the customers on the review they made about the hotel. Ladhari (2009) investigated service quality along with customer satisfaction and behavioural intentions. In this study, favourable behavioural intentions included paying a premium price while the opposite includes spending less money. Although the study of Ladhari (2009) included service quality factors and customers' willingness to spend more money, there was no investigation of the relation between price and PS quality.

The results of the present study highlight the differences between customer perceptions of expensive and inexpensive hotels, regarding service characteristics. This determination helps hotel managers and travel agents to have a clear idea of what expectations each customer has from hotel services, based on the amount of money he or she chooses to spend. Additionally, by identifying what dimensions are more important (frequently reported) on travel agency websites, hotel managers can focus on them without placing unnecessary emphasis on aspects, which are proven to be less important; especially for hotels focusing exclusively on each one of the customer categories. In particular, this study revealed that customers of inexpensive hotels consider tangibility as the most important drawback dimension on their willingness to pay for an economy hotel. To satisfy this category of customers, economy hotels should focus investments on the quality of their hotel rooms that may include room design, space and other facilities, which can be investigated by a qualitative in depth analysis of the customer reviews.

Managers of expensive hotels should primarily pay attention to physical facilities in order to increase the offered quality, since customers that choose these hotels expect modern looking equipment and appealing facilities. In addition, expensive hotels should employ well-trained staff at all positions. The staff should be able to resolve any problems that may occur promptly. Managers should invest in both physical facilities and human resources. On the other hand, managers of inexpensive hotels that do not have big amount of money to invest should focus on offering customers with caring and personalised attention in an attempt to increase their satisfaction. 


\subsection{Limitations and future work}

While this study has used rigorous data collection and analysis procedures, some limitations need to be highlighted, which are worthy to be mentioned in the results interpretation and for consideration in future research. This study reveals the important service quality dimensions of hotels as identifying under the absolute price lens, through travel reviews posted on a travel agency website (Booking.com). However, online reviews may not provide the whole view of hotel customers' opinions. For instance, it is possible that there are customers who were delighted (or opposite) tended to write extensive reviews. Nevertheless, promotions to encourage posting online reviews by booking websites have provided the websites with better representation of customers (Ye et al., 2011). Additionally, several studies (Zhang et al., 2011; Vermeulen and Seegers, 2009) have used reviews to infer service quality. The differentiation of customers of expensive and inexpensive hotels was made based on the prices exhibited at the time of the data collection; without taking into account any potential special offer made to the customers composing the reviews. Based on this study, future research should be carried out using more service quality dimensions and investigating other parameters (i.e., hotel star rating, age, etc.). In addition, future research could enhance our understanding as to the significance of these contemporary issues by conducting quantitative survey to canvas the opinions and weighting of these issues.

\section{Acknowledgements}

The authors would like to thank A. Pateli who helped in earlier phases of this project.

\section{References}

Akbaba, A. (2006) 'Measuring service quality in the hotel industry: a study in a business hotel in Turkey', Hospitality Management, Vol. 25, No. 2, pp.170-192.

Akerlof, G.A. (1970) 'The market for 'lemons': quality uncertainty and the market mechanism', Quarterly Journal of Economics, Vol. 84, No. 3, pp.488-500.

Albacete-Sáez, C.A., Fuentes-Fuentes, M.M. and Lloréns-Montes, F.J. (2007) 'Service quality measurement in rural accommodation', Annals of Tourism Research, Vol. 34, No. 1, pp.45-65.

Bajari, P. and Hortacsu, A. (2004) 'Economic insights from internet auctions: a survey', Journal of Economics Literature, Vol. 42, No. 2, pp.457-486.

Berry, L.L., Wall, E.A. and Carbone, L.P. (2006) 'Service clues and customer assessment of the service experience: lessons from marketing', Academy of Management Perspectives, Vol. 20, No. 2, pp.43-57.

Bitner, M.J. and Hubbert, A.R. (1994) 'Encounter satisfaction versus overall satisfaction versus quality', Service Quality: New Directions in Theory and Practice, pp.72-94.

Bojanic, D.C. (1996) 'Consumer perceptions of price, value and satisfaction in the hotel industry: an exploratory study', Journal of Hospitality \& Leisure Marketing, Vol. 4, No. 1, pp.5-22.

Briggs, S., Sutherland, J. and Drummond, S. (2007) 'Are hotels serving quality? An exploratory study of service quality in the Scottish hotel sector', Tourism Management, Vol. 28, No. 4, pp.1006-1019. 
Buhalis, D. and Licata, M.C. (2002) 'The future eTourism intermediaries', Tourism Management, Vol. 23, No. 3, pp.207-220.

Carvell, S.A. and Quan, D.C (2008) 'Exotic reservations - low-price guarantees', International Journal of Hospitality Management, Vol. 27, No. 2, pp.162-169.

Chang, J. (2009) 'Taiwanese tourists' perceptions of service quality on outbound guided package tours: a qualitative examination of the SERVQUAL dimensions', Journal of Vacation Marketing, Vol. 15, No. 2, pp.165-178.

Christou, E. (2006) 'A qualitative analysis of consumer attitudes on adoption of online travel services', Tourism: An International Interdisciplinary Journal, Vol. 54, No. 4, pp.323-331.

Clerides, S., Nearchou, P. and Pashardes, P. (2008) 'Intermediaries as quality assessors: tour operators in the travel industry', International Journal of Industrial Organization, Vol. 26, No. 1, pp.372-392.

Collins, M. and Parsa, H.G. (2006) 'Pricing strategies to maximize revenues in the lodging industry', International Journal of Hospitality Management, Vol. 25, No. 1, pp.91-107.

Cunningham, L.F., Young, C.E. and Lee, M. (2002) 'Cross-cultural perspectives of service quality and risk in air transportation', Journal of Air Transportation Management, Vol. 7, No. 1, pp.3-26.

Devaraj, S., Fan, M. and Kohli, R. (2002) 'Antecedents of B2C channel satisfaction and preference: validating e-commerce metrics', Information Systems Research, Vol. 13, No. 3, pp.316-333.

Dodds, W.B., Monroe, K.B. and Grewal, D. (1991) 'Effects of price, brand, and store information on buyers' product evaluations', Journal of Marketing Research, Vol. 28, No. 3, pp.307-319.

Fernández, M.C.L. and Bedia, A.M.S. (2005) 'Applying SERVQUAL to diagnose hotel sector in a tourist destination', Journal of Quality Assurance in Hospitality \& Tourism, Vol. 6, No. 1, pp.9-24.

Gretzel, U. and Yoo, K.H. (2008) 'Use and impact of online travel reviews', in O'Connor, P., Höpken, W. and Gretzel, U. (Eds.): Information and Communication Technologies in Tourism, pp.35-46, Springer Wien, New York.

Hartman, R.S. (1989) 'Hedonic methods for evaluating product design and pricing strategies', Journal of Economics and Business, Vol. 41, No. 3, pp.197-212.

Johnston, R. (1995) 'The determinants of service quality: satisfiers and dissatisfiers', International Journal of Service Industry Management, Vol. 6, No. 5, pp.53-71.

Juwaheer, T.D. (2004) 'Exploring international tourists' perceptions of hotel operations by using a modified SERVQUAL approach - a case study of Mauritius', Managing Service Quality, Vol. 14, No. 5, pp.350-364.

Kumar, M., Kee, F.T. and Charles, V. (2010) 'Comparative evaluation of critical factors in delivering service quality of banks', International Journal of Quality \& Reliability Management, Vol. 27, No. 3, pp.351-377.

Ladhari, R. (2009) 'Service quality, emotional satisfaction, and behavioural intentions: a study in the hotel industry', Managing Service Quality, Vol. 19, No. 3, pp.308-331.

Lin, Y. and Su, H. (2003) 'Strategic analysis of customer relationship management - a field study on hotel enterprises', Total Quality Management \& Business Excellence, Vol. 14, No. 6, pp.715-731.

Lombard, M., Snyder-Duch, J. and Campanella Bracken, C. (2010) Practical Resources for Assessing and Reporting Inter-coder Reliability in Content Analysis Research Projects [online] http://astro.temple.edu/ lombard/reliability/ (accessed 25 October 2012).

Lowengart, O. and Mizrahi, S. (2000) 'Applying international reference price: market structure, information seeking and consumer welfare', International Marketing Review, Vol. 17, No. 6, pp.525-533.

Mayring, P. (2000) 'Qualitative content analysis', Forum: Qualitative Social Research, Vol. 1, No. 2 [online] http://www.qualitative-research.net/index.php/fqs/article/view/1089/2385 (accessed 25 August 2012). 
Monty, B. and Skidmore, M. (2003) 'Hedonic pricing and willingness to pay for bed and breakfast amenities in southeast Wisconsin', Journal of Travel Research, Vol. 42, No. 2, pp195-199.

Oh, H. (2003) 'Price fairness and its asymmetric affects on overall price, quality, and value judgments: the case of an upscale hotel', Tourism Management, Vol. 24, No. 4, pp.387-399.

Oliver, R.L. (1980) 'A cognitive model of the antecedents and consequences of satisfaction decisions', Journal of Marketing Research, Vol. 17, No. 4, pp.460-469.

Parasuraman, A., Berry, L.L. and Zeithaml, V.A. (1991) 'A refinement and reassessment of the SERVQUAL scale', Journal of Retailing, Vol. 67, No. 4, pp.420-450.

Parasuraman, A., Zeithaml, V.A. and Berry, L. (1985) 'A conceptual model of service quality and its implication for future research', Journal of Marketing, Vol. 49, No. 4, pp.41-50.

Parasuraman, A., Zeithaml, V.A. and Berry, L. (1988).'SERVQUAL: a multiple-item scale for measuring consumer perceptions of service quality', Journal of Retailing, Vol. 64, No. 1, pp. $12-40$.

Pizam, A. and Ellis, T. (1999) 'Customer satisfaction and its measurement in hospitality enterprises', International Journal of Contemporary Hospitality Management, Vol. 11, No. 7, pp.326-339.

Sigala, M. (2009) 'E-service quality and Web 2.0: expanding quality models to include customer participation and inter-customer support', The Service Industries Journal, Vol. 29, No. 10, pp.1341-1358.

Strinham, B.B. and Gerdes, J. (2010) 'An analysis of word-of-mouse ratings and guest comments of online hotel distribution sites', Journal of Hospitality Marketing and Management, Vol. 19, No. 7, pp.773-796.

Sweeney, J.C. and Soutar, G.N. (2001) 'Consumer perceived value: the development of a multiple item scale', Journal of Retailing, Vol. 77, No. 2, pp.203-220.

Vermeulen, I.E. and Seegers, D. (2009) 'Tried and tested: the impact of online hotel reviews on consumer consideration', Tourism Management, Vol. 30, No. 1, pp.123-127.

Voss, C.A. (2003) 'Rethinking paradigms of service: service in a virtual environment', International Journal of Operations \& Production Management, Vol. 23, No. 1, pp.88-105.

Webster, C. (1991) 'Influences upon consumer expectations of services', Journal of Services Marketing, Vol. 5, No. 1, pp.5-17.

Yacouel, N. and Fleischer, A. (2012) 'The role of cybermediaries in reputation building and price premiums in the online hotel market', Journal of Travel Research, Vol. 51, No. 2, pp.219-226.

Yang, C.C. and Yang, K.J. (2011) 'An integrated model of value creation based on the refined Kano's model and the blue ocean strategy', Total Quality Management \& Business Excellence, Vol. 22, No. 9, pp.925-940.

Ye, Q., Law, R. and Gu, B. (2009) 'The impact of online user reviews on hotel room sales', International Journal of Hospitality Management, Vol. 28, No. 1, pp.180-182.

Ye, Q., Law, R., Gu, B. and Chen, W. (2011) 'The influence of user-generated content on traveler behavior: an empirical investigation on the effects of e-word-of-mouth to hotel online bookings', Computers in Human Behavior, Vol. 27, No. 2, pp.634-639.

Ye, Q., Li, H., Wang, Z. and Law, R. (2012) 'The influence of hotel price on perceived service quality and value in e-tourism: an empirical investigation based on online traveler reviews', Journal of Hospitality and Tourism Research.

Zeithaml, V.A. and Berry, L.L. (1993) 'The nature and determinants of customer expectations of service', Journal of the Academy of Marketing Science, Vol. 21, No. 1, pp.1-12.

Zhang, Z., Ye, Q. and Law, R. (2011) 'Determinants of hotel room price: An exploration of travelers' hierarchy of accommodation needs', International Journal of Contemporary Hospitality Management, Vol. 23, No. 7, pp.972-981. 


\section{Notes}

1 http://travel.usnews.com/Rankings/Worlds_Best_Vacations/. 